\title{
Slovaropisje klasičnih jezikov na Slovenskem v 16. stoletju
}

\author{
Matej HriberšeK \\ Univerza v Ljubljani, Filozofska fakulteta, Aškerčeva 2, \\ SI-1000Ljubljana, matej.hribersek@fff.uni-lj.si
}

\begin{abstract}
Najzgodnejše vire slovenske klasične leksikografije najdemo v nekaterih ohranjenih ostankih iz srednjega veka in v delih slovenskih protestantskih piscev (Abecedarium, Otročja biblija, Ljubljanska začetnica, Register $k$ Bibliji), vendar se slovenska leksikografija začne resnično šele z delom Dictionarium quatuor linguarum, avtorja Hieronima Megiserja.
\end{abstract}

The origins of classical language lexicography in Slovenia may be found in a few remnants from the Middle Ages and in the works by Slovene Protestant writers (Abecedarium, Otročja biblija, Ljubljanska začetnica, Register to Bible). However, the real beginning of Slovene lexicography is the work Dictionarium quatuor linguarum by Hieronymus Megiser.

Ključne besede: klasični jeziki, latinščina, slovaropisje, Trubar, Megiser, protestanti

Key words: Classical languages, Latin, Lexicography, Trubar, Megiser, Protestants

Zgodovina slovenskega slovaropisja je precej zapletena in marsikaj je pri njenem raziskovanju še nedorečenega, najsi gre za slovaropisje slovenskega jezika ali za slovaropisje klasičnih jezikov. Dejstvo pa je, da se slovenski slovaropisni dosežki v srednjem veku in na začetku novega veka nikakor ne morejo meriti $\mathrm{z}$ dosežki večjih evropskih ljudstev. Kljub temu pa $\mathrm{v}$ obdobju, ki je zajeto $\mathrm{v}$ pričujočo predstavitev, na tem področju najdemo prve zametke in tudi prve vidnejše slovarske dosežke. Slovensko besedje so slovenski avtorji črpali iz lastnega znanja in vedenja, tuji avtorji so se opirali nanje; gradivo za latinsko besedje pa so slovaropisci črpali iz evropskih slovarjev.

Ali se je bilo mogoče v 16. stoletju, v obdobju protestantizma, na Slovenskem že nasloniti na srednjeveško slovaropisno tradicijo? Žal ne. V srednjem 
veku ni - po doslej zbranih podatkih - na naših tleh nastal noben slovar za klasične jezike, ki bi vključeval tudi slovensko besedje. Krajših slovarčkov ali seznamov besed k posameznim besedilom najdemo $\mathrm{v}$ srednjeveških rokopisih kar nekaj. Eden takih je t. i. Rinijev kodeks, ki ga hrani Bibliotheca Marciana v Benetkah ${ }^{1}$ uvodnemu besedilu v tem rokopisu (naslov: Liber de simplicibus Benedicti Rinii medici et philosophi Veneti) sledi abecedno kazalo strokovnih terminov, ki bralce usmerjajo $\mathrm{k}$ oštevilčenim podobam rastlin, na njihovi hrbtni strani pa najdemo med poimenovanji v različnih jezikih tudi slovanske (slovenske?) izraze (Bezlaj 1973/74). Med slovarji, ki so nastali na slovenskem ozemlju, velja izpostaviti 463 folijev obsegajoči Vocabularium latinum meniha in profesa Valentina Suesstrunkla, ki je živel in deloval v samostanu v Žičah (Golob 2006: 108-109). ${ }^{2}$ Med odmevnejšimi pomniki slovaropisne dejavnosti na naših tleh v srednjem veku je tudi kodeks št. 46, ki ga hrani Narodna in univerzitetna knjižnica Ljubljana. Gre za kodeks iz kartuzijanskega samostana v Bistri, ki po oceni Milka Kosa (1931: 71-73) izvira iz 14. do 15. stoletja. Vključuje več manjših latinskih vokabularjev in nekaj odlomkov o latinski slovnici. ${ }^{3}$ Najobsežnejši je prvi vokabular v kodeksu, ki obsega 40 strani (f. 103-122') in je delno verzificiran, pisan v elegičnih distihih in heksametrih; obsega skupno 960 verzov, v katerih pojasni okoli 1000 besed. Slovarček je latinsko-latinski; o slovenskem besedišču ni sledi. Je pa nedvomen dokaz, da so $\mathrm{v}$ samostanih na naših tleh nastajala tovrstna dela, ki so se $\mathrm{v}$ teku časa na tak in drugačen način izgubila. Odprto ostaja vprašanje, ali je kateri od njih vključeval tudi slovensko besedje, kajti kontemplativni redovi (kartuzijani, cistercijani, benediktinci) so glede na svoje delovanje, ki je bilo usmerjeno predvsem na vzgojo in izobraževanje znotraj redov samih in na delovanje med višjimi sloji družbe, gojili predvsem latinščino in nemščino. Ni pa izključeno.

Obdobje protestantizma sovpada s humanizmom, z obdobjem, ko oba klasična jezika doživita svoj preporod. V krogih humanistov se je ob odkrivanju, zbiranju in prepisovanju rokopisov z deli pozabljenih ali skozi pozno antiko in srednji vek izgubljenih antičnih in srednjeveških piscev začelo intenzivno ukvarjanje z latinskim in grškim jezikom ter grško in rimsko književnostjo. Latinščina, lingua Franca srednjega veka, je kljub vse večjemu uveljavljanju nacionalnih jezikov v cerkvenem okolju in krogih izobražencev ter pogosto tudi v politiki še vedno ohranjala svoj dominantni status, vendar pa znanje latinščine ni bilo več samoumevno in avtomatizirano. $Z$ novimi odkritji besedil antičnih in poznejših avtorjev ter zbiranjem raznovrstnega sekundarnega (epigrafskega idr.) gradiva se je večalo vedenje o antiki. Ob zbiranju del rimskih klasikov, ki je bilo ena od pomembnejših dejavnosti številnih humanistov, in ob odkrivanju grških piscev, ki se je še posebej okrepilo po turškem zavzetju Konstantinopla 1. 1453 in eksodusu grških učenjakov na zahod, se je širil tudi obseg besedja in

\footnotetext{
${ }^{1}$ Signatura: Narodna knjižnica sv. Marka, Mss. latini Vl. 6, № 59; manoscritti marciani 2548.

${ }^{2}$ Rokopis slovarja hranijo v Gradcu (Ms 988).

${ }^{3}$ Za natančnejšo predstavitev kodeksa in v njem ohranjenega gradiva gl. Gantar 1970.
} 
pojavila se je potreba po slovarjih. Slovarji in glosarji so seveda obstajali že prej, vendar nobeden med njimi ni ne po obsegu ne po uporabnosti dosegel takšnega uspeha in razmaha kot slovarji, ki so nastali ali vsaj začeli nastajati v obdobju humanizma. Slovarsko delo učenjakov tega obdobja je pionirsko in celo z današnjega vidika so njihovi dosežki v marsikaterem pogledu markantni; to niso bili nekajletni projekti, ampak največkrat življenjski dosežki posameznikov, ki so premogli dovolj potrpežljivosti in volje, da so se spopadli z drobnjakarskim in zamudnim delom izpisovanja, določanja pomenov in njihove klasifikacije.

Med pomembnejšimi evropskimi slovarji za klasične jezike v tem obdobju je treba omeniti dva. Prvi je slovar italijanskega leksikografa, avguštinskega meniha Ambrogia Calepina (Ambrosius Calepinus), ki je prvič izšel 1. $1502 \mathrm{v}$ Reggiu. Doživel je številne ponatise, predelave in dopolnitve ter postal v končni fazi celo enajstjezični slovar; bil je taka uspešnica, da je ime »Calepinus« postalo skupno ime oz. sinonim za slovar ali leksikon nasploh. ${ }^{4}$ Avtor drugega slovarja je švicarski humanist Peter Hasenfuß; po polatinjeni verziji njegovega priimka je slovar dobil tudi ime Dasipodijev slovar (Dasypodius). Slovar je prvič izdal 1. 1535, potem pa je izhajal še v številnih izdajah in predelavah do druge polovice 17. stoletja (nazadnje je bil ponatisnjen 1. 1995). ${ }^{5}$ Kateri slovarji

${ }^{4}$ Zaradi izjemne uspešnosti in uporabnosti je slovar doživel toliko različnih predelav in je ohranjen pod toliko različnimi naslovi, da je njegovo zgodovino zelo težko spremljati. Kot Dictionarium latinum ali samo Dictionarium je v letih med 1502 in 1663 doživel 32 različnih izdaj; kot Dictionarium copiosissimum je med letoma 1516 in 1521 doživel 7 izdaj; pod naslovom Latinae atque adeo etiam graecae linguae Dictionarium je izšel 1.1546 in 1550 v Baslu; kot Lexicon je med letoma 1521 in 1718 izšel 12-krat; kot Dictionarium linguae latinae ali Latinae linguae dictionarium je med letoma 1509 in 1663 doživel 19 izdaj; kot Dictionarium latinae italicae gallicae et hispanicae je izšel dvakrat v Benetkah (1579 in 1585); kot Pentaglottos (hoc est, quinque linguis, nempe Latina, Graeca, Germanica, Flandrica, \& Gallica) dvakrat v Antwerpnu (1545 in 1546); kot Dictionarium ... in quo latinis dictionibus adiectae sunt graecae, gallicae, italicae et hispanicae je izšel 1.1572 v Antwerpnu in 1593 v Benetkah; kot Dictionarium latinum hebraeum graecum gallicum germanicum 1.1602 v Benetkah; kot Dictionarium hexaglottum dvakrat v Baslu (1567 in 1568); kot Dictionarium linguarum septem ali Dictionarium septem linguarum 5-krat v Baslu (med 1568 in 1579), 7-krat v Benetkah (med 1612 in 1689) in 10-krat v Padovi (med 1708 in 1779); pod naslovom Calepinus septem linguarum ali Septem linguarum calepinus v Padovi in Benetkah (med 1741 in 1781); kot Dictionarium octo linguarum 3-krat (med 1584 in 1681) v Baslu, Parizu in Lyonu; kot Dictionarium octolingue 2-krat v Genfu (1609 in 1620) ter 6-krat v Lyonu (med 1634 in 1681); pod naslovom Linguarum novem Romanae, Graecae, Ebraicae, Gallicae, Italicae, Germanicae, Hispanicae, Anglicae, Belgicae Dictionarium 1. 1654 v Leydnu; kot Dictionarium decem linguarum 6-krat med 1585 in 1590 (Lyon, Genf, Basel; ponatis v Budimpešti 1912) in kot Dictionarium undecim linguarum 8-krat v Baslu med letoma 1551 in 1627.

${ }^{5}$ Slovar je pod naslovom Dictionarium Latinogermanicum oz. Dictionarium Latinogermanicum et vice versa Germanicolatinum med letoma 1535 in 1667 doživel 25 izdaj. Kot Dictionarium Germanico-Latinum priori Latino-Germanico vice versa respondens je izšel 1. 1556 v Antwerpnu. Pod naslovom Dictionarium triglotton (lat. graec. germ.) oz. pozneje Dasypodius Catholicus (Dictionarium Latino-Graeco-Germanicum, nec non 
so ali bi lahko neposredno vplivali na delo slovenskih protestantskih piscev, lahko zgolj ugibamo; več podatkov o tem nam nudijo ohranjeni katalogi univerzitetnih knjižnic, na katerih so se šolali, nedvomno pa so bili v času svojega šolanja in delovanja seznanjeni z vsem aktualnim slovarskim gradivom tega obdobja. Z delom slovenskih protestantov in protestantov, ki so delovali na Slovenskem, pa niso povezani samo začetki slovaropisja slovenskega jezika, ampak tudi začetki slovaropisja klasičnih jezikov.

Enotnega mnenja o tem, kje so začetki slovenskega slovaropisja, ni. V večini primerov gre za manjša dela (najsi gre za slovensko ali latinsko besedišče), prvi večji zbirki slovenskega besedja pa sta Register k Dalmatinovi Bibliji in Bohoričeva slovnica. Prvih seznamov besed ali manjših glosarjev s slovenskim in z latinskim besedjem še ne moremo šteti za slovarska dela, ampak zgolj za zametke, ki so bili osnova za nastanek prvih pravih slovarjev. Prvi tak zametek je Trubarjev 1. 1550 izšli opismenjevalni priročnik Abecedarij oz. Abecednik. Vendar pa je v tem delcu, ki je ohranjeno v samo enem izvodu (hrani ga mestna knjižnica v Schaffhausnu v Švici) vse premalo slovarskih prvin, da bi mu lahko v zgodovini slovaropisja pripisali večji pomen (Kmecl 2000: 5, 7-9).

Drugo podobno delo je Kreljeva Otročja biblija (Otrozhia Biblia), izšla 1566, imenovana tudi Kreljev katekizem. O tem delcu je pri nas prvi obširneje pisal France Kidrič (1924a), in sicer po zaslugi N. B. Jopsona, ki mu je poslal popis primerka iz zbirke v British Museumu, prepis vsega slovenskega in hrvaškega teksta ter fotografijo naslovne strani. Vsebina je - razen v naslovu - označena še enkrat: Catechisis quinque linguarum. Na začetku knjige (Kidrič (1924b: 127-128) dokazuje, da je izdajatelj in prireditelj gotovo Krelj) avtor v uvodu seznani uporabnika z abecedo (Alphabetum Slavonicum) in izgovorom nekaterih zlogovnih kombinacij. Uvod obsega: a) male in velike latinske črke, b) imena slovenskih črk (nomina litterarum slavicarum), c) samoglasnike (vocales; a, e, $\mathrm{ij}, \mathrm{i}, \mathrm{o}, \mathrm{u}, \mathrm{e}, \mathrm{e}, \mathrm{ia}, \mathrm{ie}, \mathrm{iu})$ in č) zloge (syllabae; ab, eb, ib, ob, jab, iub, bab ...). Sledi slovarček (vocabula) v latinskem in slovenskem jeziku, ki obsega samo 24 besed (Bog, Nebo, Svesda, Luna, Semlia, Shivot, Smert, Dusha, Hisna, Drushina ...); nedvomno je bil prekratek, da bi ga lahko uporabljali za preparacije latinskih besedil, a dovolj, da je pojasnjeval nekatere ključne verske pojme in simbole, pomembne za razumevanje vsebine. Na koncu delca so še dicta, 1 latinski rek in 4 slovenski reki. Domnevno je bil abecedar zasnovan tako, da bi ga lahko - vsaj delno - uporabljali tudi hrvaški otroci (Kidrič 1924a: 121-123). Sama knjiga je v katekizemskem delu, ki se ponavlja v petih jezikih, odraz tedanjega jezikovnega stanja in položaja slovenščine v odnosu do jezikov, s katerimi je bila v neposrednem stiku: nemščine, italijanščine,

Germanico-Latinum) je izšel 9-krat med letoma 1567 in 1709, prvič v Antwerpnu, 8-krat pa v Kölnu. Kot Dictionarium Latino-Germanico-Polonicum je izšel 1. 1642 v Gdansku, doživel pa je še nekaj predelav za šolsko rabo (npr. Nomenclatura Rerum Domesticarum in usum studiosae iuventutis, Latina, Boèmica, Germanica lingua breviter collecta, Olomouc 1560, in Lexikon graecolatinum in usum iuventutis Graecarum literarum studiosae, Straßburg 1539; ...). 
hrvaščine in latinščine (Orožen 1996: 161-162). Na ljubljanski stanovski šoli so jo uporabljali vse od izida do Bohoričeve Ljubljanske začetnice v osemdesetih letih 16. stoletja (domnevno okrog 1580).

Resničen napredek v tem oziru je pomenila Ljubljanska začetnica (Elementale Labacense) Adama Bohoriča, ki jo je avtor dopolnil še s kratkim priročnim slovarčkom z naslovom Besedišče (tudi Besedje ali Imenje; prim. Gjurin 1987: III) treh jezikov (Nomenclatura trium linguarum). Ni znano, kje je bila knjiga tiskana, verjetno pa v Ljubljani pri Janžu Mandelcu. Edini doslej izpričani izvod tega dela, ki ga je prof. Adolf Robida opisal kot »zelo tank/o/ knjižic/o/ v obliki male $8^{0}$ « (Kidrič 1924c: 128), je bil 1.1900 prodan pri ljubljanskem antikvarju Fischerju na Nizozemsko za 100 guldnov; od tedaj naprej so številni slovenisti delo brez uspeha iskali. Polni naslov dela je: Ljubljanska začetnica z besediščem treh jezikov: latinskega, nemškega in slovenskega (Elementale Labacense cum nomenclatura trium linguarum latinae, germanicae et sclavonicae). Kdaj točno naj bi delo nastalo, ni znano; domnevno med letoma 1575 in 1580; vsekakor ne pred 1. 1575 in ne po 1. 1582. Prvič jo omenja vodja ljubljanske stanovske šole Nikodem Frischlin v učnih redih ljubljanske protestantske stanovske šole (gl. Kidrič 1924d); na osnovi teh Kidrič dokazuje vsaj približno letnico nastanka. V Frischlinovem 3. učnem načrtu z dne 20. avgusta 1583 se v seznamu knjig za 1. razred omenja Elementale, a je prečrtano Latino-Germanicum, ob strani pa je z drugim črnilom dopisano Labacense cum annexa Nomenclatura trium linguarum. 20. decembra 1583 je komisija, ki je načrt ocenjevala, sklenila, naj se sodelavce povpraša, ali ne bi kazalo zaradi slovenskega jezika uporabljati v prvem razredu tudi Bohoričev Elementale; rektorju Frischlinu so člani komisije naročili, naj zaradi vaj v tem jeziku dovoli uporabo učbenika Elementale Labacense cum Nomenclatura trium linguarum latinae germanicae et sclavonicae. Šolski red (Elementale se v njem večkrat omenja) je bil sprejet 15. februarja 1584 (Kidrič 1924c: 128). Začetnica, na katero je prvi opozoril Vodnik v Zgodovini vojvodine Kranjske (Vodnik 1809: 45; Kidrič 1924c: 129-130), ${ }^{6}$ slovenski pendant $\mathrm{k}$ latinski tabuli elementaris iz 1. 1575, je abecedar za osnovni pouk branja latinščine, nemščine, zelo verjetno tudi slovenščine, Besedišče pa je latinsko-nemško-slovenski slovarček za učenje latinskih besed s pomočjo slovenskega ali nemškega maternega jezika, morda tudi obratno, za učenje nemških besed s pomočjo slovenščine; ni znano, ali je bilo besedje urejeno po abecednem vrstnem redu ali po predmetih. Učenci 1. razreda so morali iz nje recitirati latinske, nemške in slovenske besede oz. se naučiti iz nje vsak dan tri do štiri besede na pamet. Torej je vsebovala precej latinskih besed, ki jim je bil dodan tudi nemški in slovenski pomen, kar pomeni, da je šlo za pravi priročni latinsko-nemško-slovenski slovarček. Frischlin v svojih pismih omenja (pismo z dne 20. avg. 1583), da je sam snoval »ein Elementale für die Abecedarios wie denn auch eine Nomenclaturam in sechs Sprachen«, torej šestjezično besedišče in med temi šestimi jeziki je bila gotovo tudi slovenščina (lat., gr.,

\footnotetext{
${ }^{6}$ Vodnik je imel v svoji zbirki šolski red iz 1. 1584 in ga je 13. julija 1795 daroval licejski knjižnici.
} 
nem., it., slov. in najbrž hrv.). Pri snovanju se je nedvomno lahko v izdatni meri naslanjal na slovensko gradivo Bohoričevega Besedišča. Ali je bilo delo natisnjeno, ni znano; prav tako tudi ni znano, zakaj se je lotil priprave takega učbenika. Če je šlo za poskus, da bi nadomestil Bohoričev učbenik, se mu ta ni posrečil. Leta 1591 pa je Frischlin v Frankfurtu izdal Trojezični besednjak (Nomenclator trilinguis): grško-latinsko-nemški. Večina tega dela je nastala v Ljubljani; verjetno je prvotno pripravljal šestjezično nomenklaturo, po spodletelem načrtu pa je delo izdal v skrajšani obliki kot trijezično nomenklaturo. Odprto pa ostaja vprašanje, ali je pri svojem delu uporabljal tudi Megiserjev slovar (Kidrič 1926).

Za slovaropisje tako slovenskega slovaropisja kot tudi slovaropisja klasičnih jezikov pa je zanimivo, da na njunem začetku ne stoji Slovenec, ampak Nemec, 1 . 1555 v Stuttgartu rojeni humanist in polihistor Hieronim Megiser. Megiserjeva prva srečanja s Slovenci segajo v osemdeseta leta 16. stoletja, v čas študija v Tübingenu, kjer se je srečal s slovenskimi protestanti: bil je sošolec in prijatelj obeh Trubarjevih sinov, Primoža in Felicijana, ter Jurija Dalmatina; slednji mu je po neuspelem iskanju službe v Nemčiji priskrbel službo pri Janžu Khislu na Fužinah pri Ljubljani, kjer je deloval do 1. 1589. Nato je živel in deloval v Gradcu, Celovcu in Frankfurtu, umrl pa je 1. 1619 v Linzu. Megiserjeva zapuščina je izjemna: 41 tiskanih del $\mathrm{z}$ več kot 58 ponatisi ter 30 rokopisov neizdanih del pove vse. ${ }^{7}$

Megiser je eden od najpomembnejših nemških ustvarjalcev 16. stoletja, ki so s svojim delom posegli tudi v slovenski prostor (Janko 1995: 322; Janko 1987: 172-173). Leta 1592, ko je od natisa prve slovenske knjige minilo 42 let, je izdal svoj Slovar štirih jezikov (Dictionarium quatuor linguarum), s polnim naslovom Dictionarium quatuor linguarum, videlicet Germanicae, Latinae, Illyricae (quae vulgo Sclavonica appelatur) \& Italicae sive Hetruscae. Auctore Hieronymo Megiser (Impressum Graecii Styriae a Iohanne Fabro; cum S. Caes. Majestatis Privilegio Octennali. Anno MDXCII.). Slovar, ki je prvi tiskani knjižni slovar in ga je posvetil cesarju Maksimilijanu, sinu nadvojvode Karla, obsega 344 strani, vanj pa je vključil 8575 besed, ki jih je zbral ob okoli 4000 latinskih in nemških geslih (Orožen, 1995: 63). Prijateljevanje s slovenskimi protestanti in delovanje na Slovenskem sta verjetno glavna razloga za njegovo zanimanje za slovenščino, delno pa ga je k temu spodbujala tudi njegova učenjaška žilica; zelo verjetno se je naučil slovensko vsaj toliko, da je lahko zapisal nekatere izraze. Koliko gradiva je zbral sam iz ustnih virov in koliko ga je črpal iz obstoječih pisnih virov, je težko, skoraj nemogoče določiti. Večinoma je posegal po dolenjskem narečju; zelo verjetno je večino besedja povzel po Dalmatinovem Registru k Bibliji in po Bohoričevi slovnici Arcticae horulae succisivae, ki sta bila njegova primarna vira (to je dokazoval že Breznik 1926: 110). Iz Registra je prepisal večino besed, jim dodal enako dialektično označbo kot Dalmatin, poleg te pa še oznako, npr. Dalm. (C 6 a), s katero je posebej

${ }^{7}$ Za natančnejši oris Megiserjevega življenja in dela gl. Elze 1885; Doblinger 1905; Stabej 1977 in tam navedeno literaturo. 
opozoril na svoj vir (Vrtovčeva 1940: 68-70). V besedišče je mešal tudi hrvatizme in panonizme, verjetno dobljene iz ustnih virov in morda iz Slovarja petih najplemenitejših jezikov Evrope Favsta Vrančića. ${ }^{8}$ Slovar je pomemben tudi zaradi dodatka, ki vključuje nekaj primerov sklanjatev in spregatev (Dictionarii quatuor linguarum Hieronymi Megiseri Appendix. Exempla aliquot declinationum et conjugationum). Doživel je še dve, dopolnjeni in razširjeni izdaji. Druga izdaja je izšla v Frankfurtu 1. 1608; drugih podatkov o njej - razen te dokazane navedbe - ni, najverjetneje pa je izšel v nespremenjeni obliki. Tretja izdaja je izšla 1. 1744 v Celovcu z znatno razširjenim naborom besed; o tem priča že naslovna stran, kjer pove, da je slovar »correctum et auctum«, »popravljen in razširjen«. Izdaja je izšla na pobudo celovških jezuitov in mecena, koroškega deželnega vladarja A Goesa, večino gradiva pa je uredil Anton Miklaviz iz Železne Kaple (Orel 1995: 245-246). Slovarju je dodanih 12.613 slovenskih besed, večino dodatkov pa je Megiser povzel iz koroškega narečja (skupaj 21.188 slovenskih izrazov) (Vrtovčeva 1940: 70-72; Orožen, 1995: 64-65).

Po Megiserjevem slovarju so posegali skoraj vsi kasnejši slovenski slovaropisci: Matija Kastelec, Gregor Vorenc, p. Hipolit Novomeški (Adam Janez Gaiger), Marko Pohlin in še neznani pisec krškega kapucinskega slovarja. Megiserjev slovar lahko označimo kot prvo pomembno slovarsko delo pri nas, tako za slovensko slovaropisje kot tudi za latinsko, saj gre za prvi primer, da je slovenščina (v naslovu pravi: »ilirščina, ki ji splošno pravijo slovenščina«) prvič enakovredno postavljena ob bok vsem trem glavnim jezikom našega srednjeveškega prostora: latinščini, nemščini in italijanščini. Zanimivo pa je, da so slovenska gesla v slovarju postavljena pred italijanskimi. Zakaj se je Megiser odločil za tak pristop? Morda zato, ker mu je bila slovenščina bližja kot italijanščina, ali pa lahko v tem vidimo tradicionalno germansko averzijo do vsega italijanskega? Odgovora ne poznamo.

Omeniti velja tudi nekaj posebnosti. Prva je ta, da sam princip večjezičnega slovarja v tem obdobju ni nobena posebnost ali redkost; to dokazujeta že omenjena Calepinov in Dasipodijev slovar in drugi slovarji, ki so nastali v tem obdobju ali po njem. Prvi slovar z identičnim naslovom kot je Megiserjev (morda se je Megiser zgledoval po njem), torej Dictionarium quatuor linguarum, je že leta 1556 izdal Valerius Cornelius (1512-1578); štirijezični nemško-latinskofrancosko-španski slovar je izšel v Louvainu s polnim naslovom: Dictionarium quatuor linguarum, teutonicae, latinae; Gallicae, \& hispanicae. Lovanii 1556. Slabega pol stoletja pozneje, leta 1641, je štirijezični latinsko-madžarsko-češko-nemški slovar na Dunaju natisnil Gregor Gelbhaar (Dictionarium quatuor linguarum, Latinae, Hungaricae, Bohemicae et Germanicae, diligenter et accurate secundum editum. Vienna 1641).

Drugo posebnost najdemo v naslovu. Z vidika latinščine je slovnična posebnost števnik štiri (lat. quattuor), ki je pisan s samo enim $t$ (quatuor), pri

\footnotetext{
${ }^{8}$ Hrvaški škof, diplomat, polihistor in izumitelj Faust Vrančić je svoj Slovar petih najplemenitejših jezikov Evrope (Dictionarium quinque nobilissimarum Europae linguarum, latinae, italicae, germanicae, dalmaticae et ungaricae) izdal 1. $1595 \mathrm{v}$ Benetkah.
} 
čemer ne gre za napako, ampak za eno od posebnosti srednjeveške latinščine, $\mathrm{v}$ kateri so se podvojeni konzonanti pogosto poenostavili ali pa so se obratno enostavni konzonanti podvojili.

Tretja posebnost pa je ta, da je knjigo natisnil graški tiskar Johannes Faber (Hans Schmidt), ki je bil tiskar protestantskih stanov.

Končno še vprašanje, ki še vedno ostaja brez odgovora: ali je bil Megiserjev slovar zgolj zbir besedja, za katerega je v svoji delovni vnemi poskrbel ta nemški polihistor, ali pa je bil tudi učni pripomoček? Ni podatkov o tem, da bi sam Megiser hotel, da bi bil slovar pomagalo za dijake latinskih šol; nedvomno pa so ga intelektualci uporabljali pri svojem delu, dijaki pa pri učenju.

Drugi za Slovence pomemben slovaropisni dosežek je Megiserjev Thesaurus polyglottus (Zaklad več jezikov ali Slovar več jezikov ali Mnogojezični slovar), ki malenkostno presega časovni okvir 16. stoletja, vendar pa ga velja omeniti zaradi njegovega pomena. Obsega skupaj 1584 strani in je na Slovenskem redkost; posvečen je avstrijski cesarski hiši, natisnjen pa je bil 1. 1603 v Frankfurtu. Slovar je dragocen kot zbir besedja in kot vir za poznejše slovarje; vanj je Megiser vključil cca. 8500 latinskih in 10.445 slovenskih besed.

Megiserjevo delo je bilo že večkrat predmet temeljitejše obravnave. Eno prvih obsežnejših obravnav, ki je zaznamovala vse poznejše razprave in predstavitve Megiserjevega dela, je pripravil Anton Breznik v svoji razpravi o slovenskih slovarjih (Breznik 1926: passim). V svojih razpravah je oba slovarja, njune posebnosti in ozadje nastanka, skupaj z Megiserjevim življenjem in delom temeljito obdelal Jože Stabej (npr. Stabej 1967 in Stabej 1977). Vida Vrtovčeva je obdelala razmerje Megiserja do drugih slovenskih protestantskih piscev in naredila primerjavo med prvo izdajo slovarja iz 1.1592 in drugo izdajo iz 1. 1744. (Vrtovčeva 1940). Omenja ga, čeprav izjemno skopo, tudi Jakob Riegler v svoji razpravi o začetkih slovenskega knjižnega jezika (Rigler 1968). Enake razprave kot Vrtovčeva, a v znatno razširjeni, poglobljeni in nadgrajeni obliki, se je lotila tudi Martina Orožen, ki je obdelala govorno in knjižno besedje v 1 . 1744 izšlem slovarju (Orožen 1989; Orožen 2003). Eugenio Coseriu je obdelal razmerje in stične točke med Megiserjem in Trubarjem (Coseriu (1986)); za izhodišče razprave je vzel trditev Anelies Lägreid, da je Megiser pri pripravi svojih slovarjev uporabljal Trubarjeva dela. Majda Merše (2006) je obdelala oba Megiserjeva slovarja na pisni in glasoslovni ravnini, njun vpliv na oblikovanje knjižne podobe slovenščine ter raznolikost znotraj knjižnega jezika, ki je razvidna iz obeh slovarjev. Irena Orel Pogačnik (1995) je na osnovi besedja, ki ga prinašata oba slovarja, obdelala razvoj slovenskega besedišča od Megiserjevega Slovarja štirih jezikov (1592) do izida Pleteršnikovega Slovensko-nemškega slovarja (1894-1895). Slovar je dostopen tudi v preurejeni posneti izdaji iz 1. 1592, za katero je 1. 1967 poskrbela Annelies Lägreid; izdaja poleg slovarskega besedila vključuje tudi uvodno študijo o Megiserjevem življenju in delu, virih za Dictionarium, o njegovem jeziku in besedišču (Lägreid 1967).

Slovenski protestanti so s svojim delom na področju slovaropisja orali ledino. Pri njih najdemo prve slovaropisne zametke in začetke, vendar omejenega slovarskega pomena; o pravih slovarjih še ne moremo govoriti. Prva dva prava 
dosežka na področju slovaropisja tako slovenskega jezika kot tudi klasičnih jezikov sta povezana z Megiserjevim delom. Njegov pomen nam razkriva tudi dejstvo, da po Megiserju kljub kar nekaj poskusom še skoraj 200 let ni izšel noben podoben slovar. Megiserjev slovar ni pomemben le zato, ker je pomagal pri ohranjanju slovenskega knjižnega besedišča vse do 19. stoletja, ampak ima tudi izjemen dokumentarni pomen za zgodovino slovenskega jezika, saj nam daje vpogled ne le v kranjsko in dolenjsko narečje, torej centralno slovensko ozemlje, ampak v razširjeni izdaji iz 1.1744 tudi v slovensko koroško knjižno različico in razvoj slovenskega jezika na Koroškem.

\section{VIRI IN LITERATURA}

France BEZLAJ, 1973/74: Liber de simplicibus Benedicti Rinij. JiS 19 (1973/74), 185-192.

Anton BREZNIK, 1926: Slovenski slovarji. Razprave Znanstvenega društva za humanistične vede v Ljubljani III (1926), 110-174.

Eugenio COSERIU, 1986: Megiser und Trubar. Simpozij »Slovenci v evropski reformaciji šestnajstega stoletja«. Ljubljana, 6.-8. 10. 1983. Ljubljana. 51-56.

DOBLINGER, Max, 1905: Hieronymus Megisers Leben und Werke. Mitteilungen des Instituts für österreichische Geschichtsforschung. XXVI. Band, Innsbruck. 431-478.

Theodor ELZE, 1885: Hieronymus Megiser. Allgemeine Deutsche Biographie, XXI. Band, Leipzig.

Kajetan GANTAR, 1970: Das älteste lateinische Wörterbuch in Slowenien. Živa antika 20 (1970), 231-240.

Velemir GJURIN, 1987: Slovensko slovarstvo do prvega knjižnega slovarja. Magistrska naloga. Filozofska fakulteta v Ljubljani.

Nataša GOLOB, 2006: Srednjeveški rokopisi iz Žičke kartuzije 1160-1560. Ljubljana.

Anton JANKO, 1987: Nemško literarno tvorstvo na Slovenskem v 16. stoletju. III. Trubarjev zbornik. Prispevki z mednarodnega znanstvenega simpozija Reformacija na Slovenskem. Ob štiristoletnici smrti Primoža Trubarja. Ljubljana, 9.-13. november 1987. 168-177.

- -, 1995: Nemška literarna ustvarjalnost na Slovenskem. Zgodovinski oris. Informativni kulturološki zbornik. Seminar slovenskega jezika, literature in kulture pri Oddelku za slovanske jezike in književnosti Filozofske fakultete. Ljubljana. 319-333.

France KIDRIČ, 1924a: 121-125 Otrozhia Biblia 1566. ČJKZ 4/1-4, 121-125.

- -, 1924b: Otrozhja Tabla (ali Biblia) o. 1580. ¿̌JKZ 4/1-4, 125-128.

- -, 1924c: Bohoričev Elementale Labacense cum Nomenclatura. ČJKZ 4/1-4, $128-130$. 
--, 1924č: Slovenske protestantske knjige v protestantski stanovski šoli v Ljubljani 1563-1598. ČJKZ 4/1-4, 130-138.

- -, 1926: Frischlin Nikodem. SBL I. 190-192.

Matjaž KMECL, 2000: Prve slovenske knjige. Žnideršič, Martin (ur.): Ob 450-letnici izida prve slovenske knjige. Faksimile prvih slovenskih knjig. Ljubljana: Slovenska knjiga. 4-14.

Milko KOS, 1931: Srednjeveški rokopisi v Sloveniji (Codices aetatis mediae manu scripti qui in Slovenia reperiuntur). Ljubljana.

Annelies LÄGREID, 1967: Hieronymus Megiser: Slovenisch-deutsch-lateinisches Wörterbuch. Neugestaltung und Faksimile der ersten Ausgabe aus dem Jahre 1592. Bearb. von Annelies Lägreid. Wiesbaden.

Majda MERŠE, 2006: Megiserjeva slovarja in oblikujoča se knjižnojezikovna norma v 16. stoletju. Stati inu obstati. Revija za vprašanja protestantizma 3-4. Ljubljana. $123-137$.

Irena OREL POGAČNIK, 1995: Razvoj slovenskega besedišča od Megiserja do Pleteršnika. XXXI. seminar slovenskega jezika, literature in kulture (26. 6.-15. 7. 1995). Zbornik predavanj. Ljubljana.

Martina OROŽEN, 1989: Govorno in knjižno besedje v Megiserjevem slovarju 1744. Slavistična revija 37. Ljubljana. 121-133.

- -, 1995: Hieronim Megiser v slovenskem slovaropisju. Koledar Mohorjeve družbe v Celovcu za navadno leto 1995. Celovec. 63-65.

- -, 1996: Poglavja iz zgodovine slovenskega knjižnega jezika: od brižinskih spomenikov do Kopitarja. Razprave. Ljubljana: Filozofska fakulteta.

--, 2003: Govorno in knjižno besedje v Megiserjevem slovarju 1744. Razvoj slovenske jezikovne misli. Zora 26. Maribor. 194-207.

Jakob RIGLER, 1968: Začetki slovenskega knjižnega jezika (The Origins of The Slovene Literary Language). Slovenska Akademija znanosti in umetnosti. Razred za filološke in literarne vede. Ljubljana.

Jože STABEJ, 1967: Začetki slovenskega slovarstva v 16. stoletju. Jezik in slovstvo 12/6, 182-188.

--, 1977: Hieronymus Megiser: Thesaurus polyglottus. Iz njega je slovensko besedje z latinskimi in nemškimi pomeni za Slovensko-latinsko-nemški slovar izpisal in uredil Jože Stabej. Ljubljana.

Valentin VODNIK, 1809: Geschichte des Herzogthums Krain. Dunaj.

Vida VRTOVČEVA, 1940: O Megiserjevem slovarju. Slovenski jezik. Glasilo Slavističnega društva III. 68-72. 


\section{SUMMARY}

An important field of scholarly activity in the Humanist period was the study of the Latin language. Although the Greeks experienced their European "renaissance" as well, the humanists' activities still were mostly concerned with Latin language and literature. This period saw the intensive collecting of linguistic material, resulting in the earliest major European dictionaries of the classical languages, the use of which far exceeded that of the older dictionaries and glossaries. Indeed, the feats of some European lexicographers were astonishing for their time: authors would dedicate their whole lives to such projects and many did not even live long enough see the publication of their works, which were eventually published by their successors. In comparison with the major European nations in the Middle Ages and the early Modern Age, Slovene lexicographical achievements are fairly modest, borrowing their dictionary material from the European models. According to the available records, the medieval libraries of present-day Slovenia did house a number of Latin dictionary manuscripts; for the Humanist period, however, there are no reports of any new lexicographical work. The earliest origins - not beginnings, though - of classical language lexicography in Slovenia may be found in the works by Slovene Protestant writers: in the Abecedarium by Trubar, Otročja biblija [A Children's Bible] by Krelj, Ljubljanska začetnica (Elementale Labacense - The Ljubljana Primer) by Bohorič - supplemented with a short reference glossary entitled Nomenclatura trium linguarum - and in Dalmatin's Register to his Bible. Interestingly, the originator of Slovene lexicography was not a Slovene but a German, Hieronymus Megiser (1555-1619), a friend of several Slovene Protestants, who lived and worked for a period at Fužine near Ljubljana as a private tutor. He is known to have written over 40 works, the most important for Slovene language and literature being his Besednjak štirih jezikov (Dictionarium quatuor linguarum - Dictionary of Four Languages). This Latin-German-Slovene-Italian dictionary may be described as the first lexicographical work of importance compiled in the area of present-day Slovenia. Indeed, its significance extends to both Slovene and Latin lexicography, since it is the first to treat Slovene on an equal footing with the three languages which surrounded and marked the Slovene regions in the Middle Ages: Latin, German, and Italian. 